Check for updates

1 University of Kent, UK

2 Institute of Population Health Sciences, Newcastle University,

Newcastle upon Tyne, UK

Correspondence to: L Hayes L.J.Hayes@kent.ac.uk

Cite this as: BMJ 2021;374:n1684

http://dx.doi.org/10.1136/bmj.n1684

Published: 08 July 2021

\section{Mandatory covid-19 vaccination for care home workers}

\author{
Unnecessary, disproportionate, and misguided \\ Lydia Hayes, ${ }^{1}$ Allyson M Pollock ${ }^{2}$
}

In a profound departure from public health norms, new law will remove the right of care home staff in England to choose whether to be vaccinated against covid-19. ${ }^{1}$ The intended next step is a rapid and massive expansion of compulsory vaccination legally to require covid-19 and flu vaccination of all frontline health and social care workers, subject to consultation. ${ }^{2}$

Official claims that "we are not forcing anyone to take the vaccine" are disingenuous. ${ }^{1}$ Care home workers who reject covid-19 vaccination will be dismissed from employment without compensation and be barred from access to their occupation. A regulatory amendment will make it unlawful for care homes to permit care workers to enter the care home premises without proof of full vaccination. ${ }^{1}$ This will impose a new duty on all registered providers of residential care to verify the medical status of each worker, including full time and part time agency staff, staff employed directly by a care home, and volunteers. It will give responsibility for compliance and enforcement to the Care Quality Commission (CQC).

The providers' associations Care England and the National Care Forum, as well as trade unions, have expressed concern that coercion is not the best way forward. ${ }^{3-6}$ Vaccination is not a panacea for safety. Safety, according to current regulatory law, is achieved through adequate staffing levels, training, equipment, cleanliness, personal protective equipment, risk assessment, and consultation with staff and residents. ${ }^{7}$ Care home residents accounted for $40 \%$ of all covid-19 deaths in the first wave and $26 \%$ in the second wave, as a result of long term problems with care home provision, including staff shortages, but also deficiencies in the pandemic response. ${ }^{8}$

Vaccination protects individuals from covid-19 and reduces the risk of transmission of disease to others. ${ }^{9}$ Vaccine efficacy against reinfection after two doses is around $85-90 \%$, efficacy against risk of hospital admission and death from covid-19 is even higher. ${ }^{910}$ Crucially, previous infection affords immunity against reinfection and provides comparable protection to vaccination. ${ }^{11}{ }^{12}$ However, the duration of protection (particularly against new variants) remains unknown after either vaccination ${ }^{13}$ or infection.

The "liberty of non-vaccination" is a principle established in UK law since 1898. It followed vigorous and widespread protest about compulsory vaccination for smallpox that was imposed by the Vaccination Act 1853. Amendments to the Vaccination Act in 1898 and 1907 provided legal recognition of conscientious objection for those who were "honestly opposed" to vaccination and noted, too, the contribution of improved sanitation to the drop in smallpox. ${ }^{14}$

Compulsory vaccination has not been attempted since in the UK. The Coronavirus Act 2020 was careful to avoid changes to the Health and Social Care Act 2008, which excluded mandatory medical treatment, including vaccination, from the secretary of state for health and social care's power. ${ }^{15}$

Wales and Scotland have rejected compulsory vaccination for care workers. Vaccine uptake for care workers in Wales is over $96 \%$ for the first vaccination and $85 \%$ for the second. ${ }^{16}$ "Virtually all" care home staff in Scotland have been vaccinated. ${ }^{17}$ Wales and Scotland have invested in systems of mandatory registration for care workers. Care worker registration aims to professionalise the sector, increase access to training, and embed a culture of continuous professional development. In England, successive ministers have rejected national care worker registration. The Department of Health and Social Care and the CQC therefore don't know who England's care workers are, and training of the care workforce is woefully inadequate. The Scientific and Advisory Group for Emergencies has recommended a threshold for minimum protection in residential care homes of $80 \%$ of care workers and $90 \%$ of residents to have had a first vaccination. ${ }^{18}$ By 20 June 2021, over $90 \%$ of care home residents in England had received two doses of a covid-19 vaccine, $84 \%$ of care workers in England had received a first dose, and $72 \%$ of care workers had received a second dose. ${ }^{19}$

The government's decision on compulsory vaccination for care home workers was based on claims of low vaccine take-up in some care homes that were subsequently echoed in media reports. ${ }^{20}$ However, closer scrutiny of most recent data shows that uptake of the first dose of covid-19 vaccination among care workers is below $80 \%$ (68-74\%) in only three upper tier local authorities in England, but these numbers are an artefact of very low numbers of staff employed by care homes in these three. For instance, the lowest uptake of the second vaccine is in Haringey, with only 355 eligible staff in its older adult care homes compared with many thousands of staff in other local authorities. ${ }^{21}$ Moreover, the government's own methodology note warns that the numbers of staff and residents who have not received the vaccine cannot be directly derived from its data. ${ }^{22}$

Civil liberty is a necessary component of strong public health. Mandatory vaccination is unnecessary and disproportionate. It will not remedy the serious shortcomings of the care sector in England. Safety can be assured only by taking steps to build trust and to mitigate outbreaks. Care workers need paid time in which to access vaccination and good training, 
decent wages (including sick pay), personal protective equipment, and strong infection control measures. Mandatory vaccination in residential care is unnecessary, disproportionate, and misguided.

Competing interests: We have read and understood BMJ policy on declaration of interests and have no interests to declare.

Provenance and peer review: Commissioned; not externally peer reviewed.

1 Department of Health and Social Care. Consultation outcome: making covid vaccination a condition of deployment in care home: government response, 16 June 2021. https:/www.gov.uk/government/consultations/making-vaccination-a-condition-of-deployment-in-older-adult-carehomes/outcome/making-vaccination-a-condition-of-deployment-in-care-homes-governmentresponse

2 NHS. Covid-19 vaccination autumn/winter (phase 3) planning. 2021. https://www.england.nhs.uk/coronavirus/wp-content/uploads/sites/52/2021/07/C1327-covid-19-vaccination-autumn-winter-phase-3-planning.pdf

3 Care England responds to mandatory vaccination. Press release, 21 May 2021. https://www.caremanagementmatters.co.uk/care-england-responds-to-mandatory-vaccination/

4 GMB. Care worker mandatory vaccinations "incredibly bad idea." 2021. https://www.gmb.org.uk/news/care-worker-mandatory-vaccinations

5 National Care Forum. NCF responds to announcement of vaccination as a condition of deployment in CQC-regulated care homes. Press release, May 2021.

6 Unison. Care staff more likely to decline jab if threatened by employers, says UNISON survey. 2021. https://www.unison.org.uk/news/press-release/2021/05/care-staff-more-likely-to-declinejab-if-threatened-by-employers-says-unison-survey

7 Health and Social Care Act (2008) (Regulated Activities) Regulations 2014. https://www.legislation.gov.uk/uksi/2014/2936/contents

8 Scobie S. Covid-19 and the deaths of care home residents. Nuffield Trust, 2021. https://www.nuffieldtrust.org.uk/news-item/covid-19-and-the-deaths-of-care-home-residents

9 Shapiro J, etal. Efficacy estimates for various COVID-19 vaccines: what we know from the literature and reports. medRxiv 2021. [Preprint.] doi: 10.1101/2021.05.20.21257461

10 Public Health England. Covid-19 vaccine surveillance report: 24 June 2021 (week 25). https://www.gov.uk/government/publications/covid-19-vaccine-surveillance-report

11 Turner JS, Kim W, Kalaidina E, etal. SARS-CoV-2 infection induces long-lived bone marrow plasma cells in humans. Nature 2021. doi: 10.1038/s41586-021-03647-4 pmid: 34030176

12 Hansen CH, Michlmayr D, Gubbels SM, Mølbak K, Ethelberg S. Assessment of protection against reinfection with SARS-CoV-2 among 4 million PCR-tested individuals in Denmark in 2020: a population-level observational study. Lancet 2021;397:1204-12. doi: 10.1016/S0140-6736(21)00575-4 pmid: 33743221

13 Baraniuk C. How long does covid-19 immunity last?BMJ2021;373:n1605. doi: 10.1136/bmj.n1605 pmid: 34193457

14 Salmon DA, Teret SP, Maclntyre CR, Salisbury D, Burgess MA, Halsey NA. Compulsory vaccination and conscientious or philosophical exemptions: past, present, and future. Lancet 2006;367:436-42. doi: 10.1016/S0140-6736(06)68144-0 pmid: 16458770

15 Hooper L. Coronavirus Act 2020: does it permit mandatory vaccinations? Garden Court Chambers. 2020. https://www.gardencourtchambers.co.uk/coronavirus-legal-news-views/coronavirus-act2020-does-it-permit-mandatory-vaccinations

16 Barnes D. No need for mandatory care workers vaccination in Wales. South Wales Argus 2021 16 Jun. https://www.southwalesargus.co.uk/news/coronavirus/19376302.no-need-mandatorycare-workers-vaccination-wales/

17 Jones G. Care workers in Scotland will not be forced to receive Covid-19 vaccination. TFN2021 Jun 18. https://tfn.scot/news/care-workers-in-scotland-will-not-be-forced-to-receive-covid-19vaccination?utm_source=scvo\&utm_medium=website\&utm_campaign=footer

18 UK Government. Commission: What are the appropriate layers of mitigation to deploy for care homes in the context of post vaccination risk landscape? 2021. https://assets.publishing.service.gov.uk/government/uploads/system/uploads/attachment_data/file/994620/S1257_SCWG_Post_Vaccination_Mitigations.pdf

19 NHS. Covid-19 vaccination statistics. Week ending Sunday 20 June 2021. https://www.england.nhs.uk/statistics/wp-content/uploads/sites/2/2021/06/COVID-19-weekly-announced-vaccinations-24-June-2021.pdf

20 Murphy. Shockingly low Covid vaccine rate in London care home staff leads to moves to make jab mandatory. Evening Standard 202116 Jun. https://www.standard.co.uk/news/politics/lowcovid-vaccination-rate-london-care-home-staff-mandatory-b940889.html

21 National Immunisation Management Service. Covid-19 weekly announced vaccinations 24 June 2021. https://www.england.nhs.uk/statistics/statistical-work-areas/covid-19-vaccinations/

22 Department of Health and Social Care. Adult social care monthly statistics, England: methodology. https://www.gov.uk/government/publications/adult-social-care-in-england-statistics-englandmethodology/adult-social-care-monthly-statistics-england-methodology 